\title{
ASSOCIAÇÃO ENTRE A DURAÇÃO DO ALEITAMENTO MATERNO E SUA INFLUÊNCIA SOBRE O DESENVOLVIMENTO DE HÁBITOS ORAIS DELETÉRIOS
}

\author{
Daniela Bernardes ${ }^{1}$ \\ Michelly Kusminskas ${ }^{2}$ \\ Donata Fernanda dos Santos ${ }^{3}$ \\ Isis de Oliveira Grangeiro ${ }^{4}$ \\ Ricardo da Silva Fagundes ${ }^{5}$ \\ Marilia Gabriela de Oliveira Lopes ${ }^{6}$
}

Resumo: O objetivo deste estudo foi identificar a presença de hábitos bucais deletérios e relacioná-la com a duração de aleitamento materno. Foi realizado um estudo retrospectivo, utilizando periódicos indexados no período de 2006 a 2016 relacionando a duração do aleitamento materno com a introdução precoce de hábitos deletérios. Houve associação estatisticamente significante entre tempo de aleitamento materno e presença de hábito bucal deletério. Conclusão: O tempo insuficiente de aleitamento está associado à presença de hábitos bucais deletérios, como: má oclusão, alterações têmporo mandibulares, atresia do palato, briquismo e interposição lingual.

Palavras-chave: Deletério; Decíduos; Aleitamentos; Má oclusão; Sucção.

\footnotetext{
${ }^{1}$ Alunos de graduação do Curso de Odontologia/FCS/UNIVAP, Brasil. E-mail: daniellabernardes@hotmail.com.

2 Alunos de graduação do Curso de Odontologia/FCS/UNIVAP, Brasil. E-mail: michelly_janaina@hotmail.com.

3 Alunos de graduação do Curso de Odontologia/FCS/UNIVAP, Brasil. E-mail: donatafernanda@gmail.com.

${ }^{4}$ Alunos de graduação do Curso de Odontologia/FCS/UNIVAP, Brasil. E-mail: isisgrangeiro@hotmail.com.

${ }^{5}$ Alunos de graduação do Curso de Odontologia/FCS/UNIVAP, Brasil. E-mail: ricardomg84@hotmail.com.

${ }^{6}$ Curso de Odontologia/FCS/UNIVAP, Brasil. E-mail: mariliaorto@gmail.com.
} 